\title{
Development of School Guidance in the People's Republic of China from 2003-2016: Meet the Social Demands
}

\author{
Bei Lyu \\ Panyapiwat Institute of Management \\ Nonthaburi, Thailand 11120
}

\author{
Huan Huang* \\ Panyapiwat Institute of Management \\ Nonthaburi, Thailand 11120 \\ *Corresponding Author
}

\begin{abstract}
- this article addresses the development of school guidance in the People's Republic of China from 2003-2016, including cultural context for the development of school guidance such as globalization, mass media and internet, cultural diversity and pluralism, structural changes in the family, and positive psychology; research fields of school guidance(policies-included); characteristics of school guidance in China, finally draws the conclusion that (i) attaching much more attention to the influence of Taoism(yin and yang), and using softness to control hardness, dynamics between guidance and discipline to effectively implement school guidance; (ii) focusing on counseling self-efficacy to ensure counselors' competencies and training effectiveness; (iii)being aware of how local and dominant culture influences teachers' beliefs in guidance and counseling and concept of guidance, counseling and discipline to successfully conduct the cross-cultural research; (iv)imitating the moral education carried out in Hong Kong, guaranteeing curriculum materials and fixed timetable to efficiently implement school guidance.
\end{abstract} China

Keywords—school guidance; school counseling; development;

\section{Cultural ConteXt For THE DeVelopment OF SCHOOL GUIDANCE IN CHINA}

\section{A. Globalization, Mass Media and the Internet}

In the face of globalization, mass media and the Internet, China is not a "closed society", but participates actively in international affairs. China joined the World Trade Organization on 11 December, 2001, a symbol of great progress in economic globalization. In 2002, China became the country to have obtained the largest amount of foreign capital in the world (He, 2003).

The Chinese people take the advantage of science and technology, which has done with the barriers in communicating with the world to facilitate a better understanding of themselves as well as others. It was reported in June 2014 that the number of Chinese Internet users was 632 million including 527 million were mobile phone users, which met the demand for commerce and service (of course education as well as medical treatment were involved). (China Internet Network Information Center (CINIC), 2014). It is impossible for many Chinese to work, study or live without the Internet. Except for the Internet, the television is also becoming a considerable resource for information, and meanwhile watching television has been an important part of life. Furthermore, Chinese television is changing into digitalization and offering more and more programs and e-media. However, television also has an obvious negative influence on young people in terms of their ideas of social roles, values and behaviors. For example, real life is simplified and misrepresented in television programs, and too many commercials and media idols fill their heads, making teenagers lose their own value orientations, independent thinking and critical ability. The mass media promoted a contest by popular vote for the "ten greatest cultural idols in 20th century China". The result shows that, in the eyes of young people today, the cultural idols are not great classical novelists, but popular TV stars (Qi, 2003). This demonstrates that the mass media, as represented by TV, has such a strong influence on young people that it is leading people's lifestyles, their ideas of materialism and patterns of consumption, and their value orientations and priorities.

The values and lifestyles of the Chinese are greatly affected by globalization and the information age. And people not only care about their own lives and their country, China, but also are coming to care about what is happening all over the world. They would like to present Chinese culture and achievements to the world and try to absorb good things from other cultures and lifestyles with an open and tolerant attitude towards cultural diversity (Lu, 2003). "Bringing in" and "Going out" have become the slogans for many fields. However, the amount of information now is too great and complicated, which including good and bad things, and comes too quickly for the Chinese to be prepared as to how to deal with it selectively. People have fantasies and are interested in new things. It seems unavoidable that young people who have not yet developed mature values, views and the ability to make moral judgements should be badly influenced. They may be influenced by the ideas of deceit, sex, violence, bad language and extremism, and turned into moral nihilists and relativists. For example, one investigation about Internet use, which involved 3000 students, aged 12-18, in 53 high schools across Beijing, found that 22 per cent claimed to have accessed pornographic websites, and 19.6 
per cent claimed to have had internet chat about sex (Hong et al., 2004).

Similar to the other developed countries, the use of computer in Taiwan is becoming the core of the school administrative procedure. Especially, the computer network is the most convenient way for linking Taiwan's thousands of schools with educational administration institute. The earliest and most important network in the department of educational is the Taiwan Academic Network(TAN), which provided a space for exchanging all academics and information of Taiwan's higher education. And almost every universities and colleges have a connection with TAN via Internet system. Considering the powerful communication function of Internet network, the federal level office of school guidance and counseling, the council of guidance and moral education, put numerous funds and resources into the establishments of Guidance Network System (GNS) since 1992.In a way, GNS is a subsystem of TAN, which consists of GNS-database(including human resource of counseling,standards for counseling, document and literature of counseling, activities of counseling and guidance,assessment and testing of counseling, analysis of special case), Withdraw Student Report System(WSRS), and Campus Information System (CIS) (Chiou, 1997).

\section{B. Cultural Diversity and Pluralism}

Cultural diversity in China has several meanings. At the first level, China is a multi-ethnic nation comprising 56 nationalities, among which the Han nationality accounts for 91 percent of the total population. At the second one, the dominant position of the former political-centered culture has been eroded, with the advent of globalization and the information age, and co-exist of traditional and modern cultures and post-modern ideas. As a result, cultural diversity is an expression of various beliefs, values and attitudes to life. At the third one, people have more opportunities to get to know and appreciate different cultures, however, this is linked with a crisis of faith and conflicts of values, in general and specifically in relation to socialism and capitalism, that is , the difference both of collectism and individualism, and of goal orientation and role orientation.

1) Collectism and Individualism: In the Chinese cultural context, counseling is implied in the Confucianism that has dominated Chinese thoughts and behaviors for over 2500 years (Ho and Ho, 1980). Concepts such as benevolence and righteousness and their implications for learning, work, family and interpersonal relationships are taught and expected to be practiced (Hwang, 1990). There is no equivalent in American education of these long accepted social and moral traditions.

In western society, belief in individual freedoms and the benefits of moral and spiritual pluralism are dominant emphases of a western oriented ideology. Counseling reflects the notion of individual freedom in the emphasis upon counseling as ideally a voluntary activity for the client. (Sue A.Stickel \& Julia Yang, 1993). Corey (1991) stated in a text widely used in counselor training, 'Counseling is not a form of indoctrination whereby practitioners persuade clients to act or feel in the "right way"'(p.18). and "counseling is not synonymous with preaching or teaching(p.19). Paisley and McMahon (2001) stated that "school counseling programs and their particular areas of emphasis have alternated based on the social, political, economic, and psychological issues facing schools, communities, families, children, and adolescents" (p. 106). Sink and MacDonald (1998) found that the majority of states in USA either had already implemented or were planning to implement statewide comprehensive guidance and counseling programs. School counseling is moving toward programs that are comprehensive and developmental. Green and Keyes' (2001) statement that "the ability of program developers and practitioners to accurately integrate developmental theory into the role and function of the school counselor may be a more complex task than previously considered" (p. 85). And Green and Keys (2001) and Paisley and McMahon (2001) are consistent with many other professionals in advocating for the importance of collaboration in school counseling, which involve school counselors collaborating with community agencies to provide mental health services. And even there is a growing trend where mental health services are provided among community agencies in school settings (Rones \& Hoagwood, 2000).

2) Goal Orientation and Role Orientation: Goal orientation refers to whether individuals primarily strive to enhance their knowledge, skills, and competence, referred to as a learning orientation, or generally attempt to demonstrate their abilities and expertise, referred to as a performance orientation. Generally, individuals who exhibit a learning orientation, focusing on advancing their competence, not fulfilling objective standards, enjoy several benefits, such as resilience to increases in workload (Van Yperen \& Janssen, 2002), creativity (Janssen \& Van Yperen, 2004), and altruism (Porter, 2005). Goal orientation affects the capacity of individuals to withstand obstacles and adjust to change. Wang and Takeuchi (2007). As Pieterse, Van Knippenberg, and Van Dierendonck (2013) showed, which of these two possibilities prevail will depend on the goal orientation of individuals. That is, when members of a team tend to adopt a learning orientation, cultural diversity tends to be positively associated with performance on assignments. When members of a team do not adopt a learning orientation or adopt a performance avoid orientation, cultural diversity tends to be negatively associated with performance on assignments. A learning orientation encourages elaboration and analysis of distinct perspectives, facilitating the benefits of diversity. People with a performance avoid orientation strive to avoid complexities and thus may feel frustrated with the diversity.

In general, although not in all circumstances, individuals with a learning orientation set more challenging, suitable, and effective goals (VandeWalle, 2001). That is, relative to individuals who report a performance orientation, individuals who report a learning orientation have been shown to set steeper sales goals, for example, ultimately enhancing sales performance. Second, goal orientation affects the type, not only the difficulty, of goals that individuals set. Several 
studies, for instance, have shown that individuals with a learning orientation tend to set goals that are intended to boost self improvement (Brett \& VandeWalle, 1999; Elliott \& McGregor, 1999). Individuals with a performance orientation, in contrast, set goals that are intended to facilitate supremacy-a goal that was unrelated to performance. This performance orientation also coincided with a reluctance to formulate strategic plans, which tends to obstruct performance (VandeWalle et al., 1999).

Role orientation is a form of computer programming aimed at expressing things in terms which are analogous to human conceptual understanding of the world. This should make programs easier to understand and maintain.

The main idea of role-oriented programming is that humans think in terms of roles. This claim is often backed up by examples of social relations. For example, a student attending a class and the same student at a party are the same person, yet he plays two different roles. In particular, the interactions of this person with the outside world depend on his current role. The roles typically share features, e.g., the intrinsic properties of being a person. This sharing of properties is often handled by the delegation mechanism(Wikipedia, 2014).

\section{Structural Changes in the Family}

In China, family life has traditionally been regarded as the most important source of children development. The onechild policy (since 1989, state population planning has required a couple to have only one child) have brought about some significant changes in the Chinese family structure and ideas about the family. The traditional Chinese family consisted of three generations, but the national population census in 1990 showed that nuclear families, comprising a husband and wife and their unmarried child, or children, formed 65.5 per cent of all families (Chen, 2002). To support the one-child policy, the major measures for birth control and birth reduction are the promotion of health education, contraceptive techniques and abortion. The great majority of city families have only one child. And there are also an increasing number of families without any children in the household, just since the husband and wife do not expect to, or cannot have a child, or their child has grown up and left the nuclear family. There are also more and more single parent families because of divorce. The traditional family respects men more than women, but the modern family is based on an equality between them and there is now an expectation that both will participate in household management and tasks. Changes in family structure and opinions about family life have indisputable influence on the new generation's upbringing and development. These children have becoming more self-centered and less cooperative, sociable, responsible and able to take care of themselves than children with siblings, since their family environments lack peer communication, and only children are often spoiled by the indulgence of parents or grandparents (Feng, 2002).On the other hand, the only child still has some good characteristics such as strong confidence and wide interests, that is, noticeable problems of socialization and behavioral habits.The more equal relationship between husband and wife in the family affects the children directly, however, urban and rural comparison shows that people living in the countryside still have a strong concept of man's superiority over woman. Rural people still want to raise a son to ensure their long-term welfare since a daughter will be married into another family, whereas a son will bring a wife into the family and stay at home. When life in rural families is permeated with such a sense of man's superiority over woman, moral education will be greatly influenced. Many children brought up in rural areas will be familiar with, and may themselves display, chauvinistic attitudes and behavior.

As for the urban child's education within the family, there often exists a 'generation gap' in many families, there are usually some considerable differences in values and views of education between parents and grandparents, which have bad influences on the child, so the two generations must engage in dialogue to establish basic common opinions. This is especially necessary as many parents are busy working and they may ask the grandparents to take care of and educate the child, which brought about some problems, such as making the child unsociable and eccentric, poor parental communication, bad behavioral traits and learning habits, poor self-control and unbalanced all-round development (Qi Wanxue \& Tang Hanwei, 2004). And urban only-children experienced significantly lower love awareness from family, higher neurotic and social depression, trait anxiety, perceived stressors, and interpersonal dependency than did urban nononly children (Chenying Liu et al., 2005).

Because of China's open-door economic reform and globalization, the largest migration has been happened in human history (Zhang,2004). Nationwide, about $15 \%$ of all rural families include at least one member who has migrated to an urban area. Under these circumstances, a large number of children left in the original rural communities by one or both parents or grandparents. According to the ecological model, a dominant theoretical framework of child development in development psychology, family socioeconomic resources, family relationships, and parenting styles in communication, support, and supervision have been shown to be important developmental factors (Wen,2008). Psychological, behavioral, and educational outcomes and the psycho-social contexts of these outcomes among children left behind by one or both of their rural-to-urban migrant parents compared to those living in non-migrant families. Left-behind children were disadvantaged in health behavior and school engagement but not in perceived satisfaction. The child's psycho-social environment, captured by family socioeconomic status, socializing processes, peer and school support, and psychological traits, were associated with, to varying extent, child developmental outcomes in rural China (Ming wen \& Danhua Lin, 2012). Except children left behind in rural, a large increasing number of children of migrant workers have flooded into urban together with their parents, who suffered from symptoms of separation anxiety, depression and generalized anxiety disorder. These risk factors included age, sex, discrimination at school, teacher's discipline and parent-child conflicts. Strategies and programs should be developed to help children of migrant workers and their parents to develop better communication 
and problem-solving skills so that both parties will experience positive interactions. Efforts must also be made to tackle discrimination at schools by developing programs that facilitate better understanding and respect among children of migrant worker and their peers and teachers in Shanghai, China (Fu Keung Daniel Wong et al., 2009). Besides, migration stress, particularly financial and employment difficulties, difficulties in interpersonal relationships, and social companionship support contributed substantially to the mental health of both male and female migrant workers ( Daniel Fu Keung Wong \& Grace Leung, 2008).

\section{The Influence of Positive Psychology and Neuroscience}

Positive psychology is a scientific study aiming to promote optimal functioning (Seligman \& Csikszentmihalyi, 2000). It is a rapidly developing field that provides empirical research in areas such as character strengths, resilience, mindsets, life meaning and positive emotions. In addition, positive psychology interventions can be used by Guidance Counselors to enhance students' well-being, reduce depression, emotional adjustment, and improve their school performance, whose interventions have been extensively used in clinical and educational settings (Seligman, Rashid, \& Parks, 2006; Freres, Gillham, Reivich, \& Shatte, 2006), they have only recently been applied to the work of Guidance Counselors. In the USA and UK educational policies have changed and programmes such as Penn Resiliency (University of Pennsylvania) has been introduced in hundreds of schools. They use positive psychology interventions to enhance students' post traumatic growth, reduce their depression and suicide rates, which is particularly relevant in view of the Mental Health Guidelines recently launched in Ireland (DES, 2013). Related research shows that positive psychology interventions may be more effective in fighting depression than traditional approaches (Seligman, Rashid, \& Parks, 2006) and are particularly beneficial for students (Sin \& Lyubomirsky, 2009).

To aim at improving research method, of course, measuring method included, rely on using the achievements of neurosciencee, since existed research mainly are based on self-reported scales, however, in the future, researchers will attach more attention to objective measuring instruments, such as eye movement technique and functional Magnetic Resonance Image( fMRI), to lay stress on the objectivity of research to the most degree.

\section{E. Curriculum Materials and Implementing}

The teaching of school guidance is not fully developed in China, but though there is only Guidelines for mental health education of primary and secondary schools was enacted by Chinese Ministry of Education (later, 2012 revised edition), there is no lack of available teaching materials and fixed time. Since too many subjects need to be squeezed into the secondary school curriculum, it seems practically impossible to establish the formal teaching of school guidance as a separate subject. However, school-based mental education in China could be strengthened by the development of sets of structured teaching materials (similar to textbook) by curriculum experts and experienced teachers, using the existing resources and under the guideline of, and with the assistance of Committee of Mental Health Education Experts in Primary and Secondary Schools in China.

Establishing a school mental health education curriculum system with Chinese characteristics requires a lengthy course of research and development. As for the current implementation of the curriculum reform and school guidance practice in China, many challenges remain. Firstly, in the global information society, especially by means of the Internet, profound consideration should be given to finding a harmonious resolution of the relationship between the diversity of cultures of the world and the development of Chinese culture. Secondly, there are many inconsistencies between teacher's theoretical knowledge and their actual teaching methods, and they lack experience of how to facilitate student's learning through practice, and should place more weight on the practice dimension of curriculum, thirdly, given fundamental social and educational differences between urban and rural locations in China, further research should be undertaken about the effects of diversity of conditions for the implementation of the new curriculum as well as to how moral education can be introduced across the curriculum in other subjects of the national curriculum, similar to moral education implemented in Hong Kong (Ho Kwok Keung, 2004). Fourthly, based on the differences between the elementary school and secondary school, further experimental research and development needs to be undertaken about the integration of elementary and secondary school approaches.

\section{RESEARCH FIELDS OF SCHOOL GUIDANCE IN CHINA FROM 2003-2013}

\section{A. Policies}

In 1999, the act that several opinions on strengthening mental health education of primary and secondary schools was enacted by Chinese Ministry of Education, which provided guidance to Basic Principle, Main tasks, Implementation Approach, Building of Teachers Forces. Psychology was identified as national first-level discipline by the academic degrees committee under the state council in 2000. In 2002, Guidelines for mental health education of primary and secondary schools was enacted by Chinese Ministry of Education ( later, 2012 revised edition), which also provided guidance to Basic Principle, Main tasks and content, Implementation Approach, and whose model was changed into state-directed development model, and moved into the stage of vigorous development. China has a threetier national licensing program, supported the Central Department of Labor including a Licensed Level Three, Level Two, and Coveted Level Counselor (Education Profs, Students to Help Implement, 2007). Chinese Educational Reform and Development Compendium(2010-2020) was enacted by the state council, which provided further guidance to curriculum reform.

\section{B. Research Fields}

Based on the Programs supported by National Office for Education and Science Planning(2003-2013), here are the following fields, the influence of network on student's 
psychological development research; students' efficient learning psychology research; psychological development of students with learning difficulties and the correction education; teachers' mental health quality of research; college, middle and primary school mental health education of cohesion research; primary and middle school students' mental health standards and evaluation system research; children and adolescent's personality evaluation system and perfect personality cultivation research; strategy research in the cultivation of creative thinking; the intervention system research of student's mental crisis; left-behind children and children of migrant workers mental development research, etc.

\section{CHARACTERISTICS OF SCHOOL GUIDANCE IN CHINA}

\section{A. Collaboration Stage: Cross-cultural Reasearch and Multi-subjects}

Psychological services for children and youths are provided by medical clinics, using the medical model of service. The review of relevant research in the People's Republic of China indicates that the present situation is similar to that found in the U.S., where professionals at the university level conduct most of the research. There are no practicing school psychologists in China, and the likelihood that this situation will change is very low, because the competition for resources is very keen, school psychology has a low priority, and educational policy is formed by political authorities (Joseph C. La Voie, 1989).

Based on the benefit of the practice of career counseling in Hong Kong and the United State (S. Alvin Leung, 2002). Researchers in both countries should collaborate and conduct cross-cultural research on theories of career development and determine aspects of these theories that are universal and aspects that are specific to a particular culture or a group of cultures. Cross-cultural research studies involving participants from both countries would allow us to compare and contrast variables in terms of their relevance across cultures. There is also need for career assessment tools to facilitate the practice of career counseling, specially, valid Chinese translations are need. Practitioners in the United States and Hong Kong have years of experience to share with their counterparts in China. Meanwhile, some forms of cultural adaptation and integration have to occur for crosscultural training in career counseling to have a lasting effect.

\section{B. Guidance and Counseling Via Internet}

The use of computer in China is becoming the core of the school administrative procedure, the computer network is the most convenient way for linking Chinese thousands of schools with educational administration institute. Considering the powerful communication function of Internet network, put numerous funds and resources into the establishments of online training and online counseling.

\section{Attach More Attention to Children Left behind in Rural and Children of Migrant Workers in Urban}

Because of China's open-door economic reform and globalization, the largest migration has been happened in human history (Zhang,2004). Nationwide, about $15 \%$ of all rural families include at least one member who has migrated to an urban area. Under these circumstances, a large number of children left in the original rural communities by one or both parents or grandparents. These left-behind children were disadvantaged in health behavior and school engagement but not in perceived satisfaction. The child's psycho-social environment, captured by family socioeconomic status, socializing processes, peer and school support, and psychological traits, were associated with, to varying extent, child developmental outcomes in rural China (Ming wen \& Danhua Lin, 2012). Except children left behind in rural, a large increasing number of children of migrant workers have flooded into urban together with their parents, who suffered from symptoms of separation anxiety, depression and generalized anxiety disorder. These risk factors included age, sex, discrimination at school, teacher's discipline and parent-child conflicts. Strategies and programs should be developed to help children of migrant workers and their parents to develop better communication and problem-solving skills so that both parties will experience positive interactions. Efforts must also be made to tackle discrimination at schools by developing programs that facilitate better understanding and respect among children of migrant worker and their peers and teachers in China (Fu Keung Daniel Wong et al., 2009).

\section{From Problems-solving Stage to Cultivation of Positive Self-consciousness}

According to the development of school guidance in China, three historical stages, in the beginning stage, the vocation guidance was a central part of guidance, whose aims at solving the problems, and the non-professional personnel used primitive methods to guide students in a nondevelopmental way. In the expansion stage, psychological guidance and life guidance put into guidance area, and professional guiders used models, instruments and tests to aid guidance in a developmental way. In the integration stage, there are two integration methods: one is the comprehensive model which contained different contents, methods and personnel, the content elements of all the states and local schools contain career development guidance competencies to master, and also individual life plans, and the other is the career model based on career guidance, to cultivate positive self-consciousness(see The Self-perception of Ability by Chinese Children in China and Hong Kong: Gender and Grade differences; Counseling values and their relationships with self-efficacy among Chinese secondary school teachers in Hong Kong) (Jing Ni, Tan Jin \& Hong Wang, 2014)

\section{CONCLUSION}

First, under the influence of Taoism(yin and yang), using softness to control hardness, dynamics between guidance and discipline. In western countries, school guidance and counseling were affected by individualism, and in Hong Kong, teachers expressed that the lack of discipline (similar to yang of Taoism) and have been looking for the better ways to positively manage students' difficult behavior(Education Convergence, 1998,2002; Boy's and Girl's Club Association, 2000; Hue,2001,2002,2005a). In China, school guidance and counseling also have been 
influenced by original culture, and traditional culture became part of the cultural construct for school guidance and discipline, for example, Taism, was founded by Lao Tze (400 BC), which places emphasis upon spontaneity and teaches that individuals should follow natural ways, and teachers also let natural potential of students be released. Besides, another Taoist strategy was "using softness to control hardness"(yi you ji gang). For example, when a class was very disruptive, as using harsh punishments and rules was likely to provoke anger and rebellious behavior. From this viewpoint, teachers should adopt "soft" strategies to manage "hard" classes, not trying to impose authority too strongly, but remain calm and using skills such as active listening and empathy.

Many teachers admitted that they had to play the two roles of guidance and discipline, whose roles included behaviors such as punishing and caring. And teachers depicted guidance and discipline just like the dynamic between yin and yang in Taosim. Guidance and discipline are interdependent, and one could nor exist without the other when the teachers manage students' behavior, they should keep the balance between yin and yang (guidance and discipline), in the same way, teacher-student relationships were interdependent and complementary, without students, teachers meant noting at all.

Second, with the globalization, mass media and the Internet, a number of cross-cultural researches about school guidance and counseling were conducted (eg. Sue A.Stickel \&Julia Yang,1993; Weiyuan Zhang et al., 2002; Hui, Eadaoin K.P., 1998; Ming Tak Hue, 2010; Zhang \& Weijun,1994), and the ethos of multiculturalism and inclusion has been advocated in education, many schools have been looking for ways to better support students with diverse backgrounds including race, culture, and socioeconomic status. It is essential to understand the cultural values and the culturally related nuances to interpret the problem. Being cross-cultural and multicultural have been regarded as the fourth phase of school guidance and counseling development, just following the other three traditional phases of psychoanalytic, behavior modification, and humanistic counseling (Pedersen, 1990, 1991). The implementation of school guidance and counseling in various contexts of helping, such as career guidance and play therapy, should be made culturally relevant, especially where group students from various cultural and ethnic backgrounds. For instance, individuals' narratives of the psycho-social aspects of "self" vary based on their cultural background. With the above statement, school guidance and counseling should be based on ideas and experiences indigenous to the culture where students have been cultivated. Therefore, it is necessary for school counselors to have a conceptual understanding of the cultural values held by their students, and to be aware of how local and dominant culture influences teachers' beliefs in guidance and counseling, and attach more attention to teachers' belief training.

Third, counseling self-efficacy is an important construct for research and evaluation in counselors' competencies and training effectiveness. The construct of counseling selfefficacy has gained much attention among counselor educators and researchers (e.g., Johnson, Baker, Kopala, Kiselica and Thompson III, 1989; Larson and Daniels, 1998; Lent et al., 2003). However, little research has investigated the validity of the Counseling Self- Estimate Inventory in the context of counseling Chinese students in schools. Since Guidelines for mental health education of primary and secondary schools was enacted by Chinese Ministry of Education (later, 2012 revised edition), the guidance teacher model has been widely established in metropolis such as Beijing, Guangzhou,Shanghai, developing the school guidance programmes and providing counseling and guidance to students in school. To compensate for the inadequacy in counseling and guidance training, short courses and seminars are run for guidance teachers by the Education Department (see Chinese Educational Reform and Development Compendium(2010-2020)). And China has a three-tier national licensing program, supported the Central Department of Labor including a Licensed Level Three, Level Two, and Coveted Level Counselor(Education Profs, Students to Help Implement, 2007). However, there has been a lack of assessment instrument for measuring guidance teachers' self-reported estimate of their counseling competencies in counseling and guidance.In addition, the development and validation of the Chinese version of the Counseling Self-Estimate Inventory (COSE) would be a significant step forward in understanding the applicability of the Western construct of Counseling Self-Efficacy to Asian contexts (Shek, 1999). Chinese-COSE will be adopted as useful indicators of the confidence in using micro-skills, process skills, coping with difficult client behavior, and cultural competencies in individual counseling self-efficacy on guidance work in China. Except for Chinese-COSE for students, it is necessary that develop Chinese-COSE for adolescents and help students in university understand and monitor the self-perceptions of their capabilities in managing various career skills.

Fourth, so far, there has been considerable confusion about the concepts of guidance and counseling (Best et al., 1977; Best, 1989; Hui, 1994). Guidance--as a process which helps students toward self-development and the making of informed choices (Miller et al., 1978; Milner, 1980)-includes all educational activities in schools, ranging from individual guidance given by teachers to the whole school curriculum. Counseling, under the umbrella of guidance, is one of the services offered for students with problems (DES, 1989, p.3). In Hong Kong, guidance has come to be considered as a way of fostering positive behavior and facilitating students in personal, social and school adjustment (Hong Kong Education Commission, 1990). On the question of mismatch in perception, the diversity of views between students and teachers, as revealed in this study, is more in terms of the magnitude of their agreement. Although teachers gave more agreement to a problem-solving and developmental view of guidance, and were more positive on the helpfulness of individual guidance and on the various means of school improvement of guidance, the differences between their views and those of students were mainly in the rating of strong agreement or agreement (Hui, 1998). The phenomena of mismatch in perception can be illuminated by employing social representation as an explanation. As 
Moscovici (1988) contends, representation is social and heterogeneous, students' views provided empirical evidence that they had no preference for either the 'referral nature' or the 'student-initiated nature' of guidance and counseling. Instead, they preferred guidance and counseling to be 'invitational in nature' (McLaughlin, 1993, p. 47), on the other hand, teachers' views on the school organization of guidance work, adjustment of teachers' workload and training in counseling for teachers, as the school's contribution to the improvement of guidance, provide empirical evidence to support the importance of the intermediate level of guidance and counseling (Hamblin, 1993).

Fifth, school guidance's curriculum materials and implementing, just like moral education carried out in Hong Kong. Moral education in Hong Kong does not usually occupy a regular slot in the school timetable. The teaching of moral education is mainly promoted through school assemblies, form teacher periods, and extra-curricular activities (Chan, 1993). A distinction may be made between moral and civic education in Hong Kong, by means of four aspects: self, self and others, self and community, and self and the political authority (Wong, 1990). Moral education focuses on the first two aspects, while civic education concentrates on the latter two aspects. Therefore, school guidance could also be implemented through school assemblies, form teacher periods, and extra-curricular activities, whose content could be adopted in the moral curriculum materials (eg. Self-understood; self and others; social competence).

Funding: This study was funded by 2013 Jiangsu province Education Science "the study of cultivating the positive emotions for children of migrant workers" (No. Cb/2013/02/019)

This article does not contain any studies with human participants performed by any of the authors.

\section{REFERENCES}

[1] Best, R. (1989). Pastoral care: some reflections and a restatement. Pastoral Care in Education, 7, 7-14.

[2] Best, R., Jarvis, C. \& Ribbins, P. (1977). Pastoral care: concept and process. British Journal of Educational Studies, 25, 124-135.

[3] Boys' and Girls' Club Association. (2000). How adolescents face up to school violence: a research report (Hong Kong, BGCA) (in Chinese).

[4] Brett, J. F., \& VandeWalle, D. (1999). Goal orientation and goal content as predictors of performance in a training program. Journal of Applied Psychology, 84, 863-873.

[5] Chen, M. D. (2002, February 2) Woguo hunyin jiating qile naxie da bianhua [What big changes were brought about in Chinese marriage and the family] Beijing Ribao [Beijing Daily], p.14.

[6] Chan, K. H. (1993). Theories and practices in education (Hong Kong, Hong Kong Baptist University, Centre for Educational Development).

[7] Chenying Liu, Tsunetsugu Munakata, and Francis N.Onuoha.(2005). Mental Health Condition Of The Only-child: A Study Of Urban and Rural High School Students in China. Adolescence. Vol. 40. No. 160, Winter 2005.

[8] China Internet Network Information Center (CINIC) (2014). Disanshisici Zhongguo hulianwangluo fazhan zhuangkuang tongji baogao [34th statistical report on internet development inChina]. Website:

/cnnic.cn/gyw m/xwzx/rdxw/2014/201407/t20140721_47439.html.

[9] Chiou, Hawjeng.(1997). Integration of the Resources of the Guidance and Counseling via Internet: Development of the "Guidance Network System(GNS)" in Taiwan. Caring in an Age of Technology. Proceedings of the International Conference on Counseling in the $21^{\text {st }}$ Century, p.10.

[10] Corey, G. (1991). Theroy and practice of counseling and psychotherapy. Pacific Grove CA: Brooks Cole.

[11] Daniel Fu Keung Wong \& Grace Leung. (2008). The Functions of Social Support in the Mental Health of Male and Female Migrant Workers in China. Health \& Social Work. Vol.33. No.4.

[12] DEPARTMENT OF EDUCATION AND SCIENCE (1989). Report of Her Majesty's Inspectors on Pastoral Care in Secondary Schools: an Inspection of Some Aspects of Pastoral Care in 1987-8. Stanmore: DES.

[13] Department of Education and Skills, Health Service Executive, \& Department of Health Ireland (DES: 2013). Well-being in Post Primary-Schools: Guidelines for Mental Health Promotion and Suicide Prevention. Retrieved from http://www.nosp.ie/Well_Being_PP_Schools_Guidelines.pdf on 18th September 2013.

[14] Education profs, students to help implement school counseling training program in China. (1001). Retrieved October 23, 2009, from Rowan University Website: http://www.rowan.edu/today/ news/index/PR/1646.

[15] Elliott, A. J., \& McGregor, H. A. (1999). Test anxiety and the hierarchical model of approach and avoidance achievement motivation. Journal of Personality \& Social Psychology, 76, 628-644.

[16] Education Convergence. (1998). Looking at student discipline (Hong Kong, Longman) (in Chinese).

[17] Education Convergence. (2002). Back to the basics: case study of students' behavior in the classrooms of Hong Kong secondary schools (Hong Kong, Contemporary Development Company) (in Chinese).

[18] Green, A., \& Keys, S. G. (2001). Expanding the developmental school counseling paradigm: Meeting the needs of the 21st century students. Professional School Counseling, 5, 84-95.

[19] Feng, X. (2002). Zhongguo dusheng zinuÈ yanjiu [A review of onlychild studies in China], Jianghai Xuekan [Jianghai Academic Journal], 5, 90-99.

[20] Fu Keung Daniel Wong, Ying Li Chang,Xue Song He. (2009). Correlates of psychological well-being of children of migrant workers in Shanghai, China. Soc Psychiat Epidemiol. 44. 815-824.

[21] Gillham, J. E., Reivich, K. J., Freres, D. R., Lascher, M., Litzinger, S., Shatté, A., \& Seligman, M. E. P. (2006). School-based prevention of depression and anxiety symptoms in early adolescence: A pilot of a parent intervention component. School Psychology Quarterly, 21(3), 323-348.

[22] Hamblin, D. (1993). The Teacher and Counseling (2nd ed). Hemel Hempstead: Simon \& Schuster.

[23] He, H. Z. (2003). Zhongguo cheng 2002 quanqiu xishou waizi zuida liangdian [China is highlighted for achieving the largest amount of foreign capital in the world in 2002]. Available online at: http:// finance.21 cn.com/news/2003-01-21/916492.html (accessed 15 August 2004).

[24] Ho,I.C. \& Ho.J.K. (1980). Philosophical foundation of school guidance and counseling. In:Wu, W.D. (Ed.), School counseling(pp.73-86). Taipei, Taiwan: Chang-Lao-Shih Press.

[25] Hong, M., Miu Y. \& Shi Y. (2004, March 14). Jingti, e wenhua qinshi qingshaonian [Be alert! Bad culture erodes young people], Jiefang Daily, Shanghai, p. 2.

[26] Hong Kong Education Commission (1990). Education Commission Report No. 4. Hong Kong: Hong Kong Government.

[27] Ho Kwok Keung \& Belinda Ho. (2004). A review of moral education curriculum materials in Hong Kong.Journal of Moral Education, Vol.33, No.4, December 2004. 
[28] Hui, E.K.P. (1994). Teaching in Hong Kong: Guidance and Counseling. Hong Kong: Longman.

[29] Hui, E.K.P.(1998). Guidance in Hong Kong schools: students' and teachers' beliefs. British Journal of Guidance \& Counseling. Vol.26, Issue 3. P435. 14p.

[30] Hwang, K.K. (1990). Self-actualization of Chinese. In:Chinese Guidance Association, Towards the $21^{\text {st }}$ Century: New Era for FuTao(pp.43-70). Taipei, Taiwan:Psychological Press.

[31] Janssen, O., \& Van Yperen, N. W. (2004). Employees' goal orientations, the quality of leader-member exchange, and the outcomes of job performance and job satisfaction. Academy of Management Journal, 47, 368-384

[32] Jing Ni, Tan Jin \& Hong Wang.(2014). An Overview of the History of Student Developmental Guidance (1900-2010). Advances in Psychology.2014, 4, 284-292.

[33] JOHNSON, E., BAKER, S.B., KOALA, M., KISELICA, M.S. \& THOMPSON III, E.C. (1989). Counseling self-efficacy and counseling competence in pre-practicum training. Counselor Education and Supervision, 28, 205-218.

[34] Joseph C. La Voie. (1989). School Psychology Research in the People's Republic of China. PROFESSIONAL SCHOOL PSYCHOLOGY, 4(2), 137-145.

[35] Larson, L.M. \& Daniels, J.A. (1998). Review of the counseling selfefficacy literature. The Counseling Psychologist, 26(2), 179-218.

[36] Lent, R.W., Hill, C.E. \& Hoffman, M.A. (2003). Development and validation of the counselor activity self-efficacy scales. Journal of Counseling Psychology, 50, 97-108.

[37] Lu, J. (2003). Yingdui quanqiuhua: tisheng wenhua zijue [Promoting our cultural consciousness to face globalization], Peking University Education Review, 1(1), 27-30.

[38] McLaughlin, C. (1993). Counseling in a secondary setting-developing policy and practice. In K. Bovair \& C. McLaughlin (Eds), Counseling in Schools: a Reader (pp. 36-51). London: David Fulton.

[39] Miller, F.W., Fruehling, J.A. \& Lewis, G.J. (1978). Guidance Principles and Services. New York: Bell \& Howell.

[40] Milner, P. (1980). Counseling in Education. London: Milner.

[41] Ming Wen \& Danhua Lin.(2012). Child Development in Rural China: Children Left Behind by Their Migrant Parents and Children of Nonmigrant Families. Chid Development. Vol.83,No.1. 120-136.

[42] Ming Tak Hue.(2010). Influence of Taoism on teachers' definitions of guidance and discipline in Hong Kong secondary schools. British Educational Research Journal. Vol.36, No.4.597-610.

[43] Moscovici, S. (1988). Notes towards a description of social representations. European Journal of Social Psychology, 18, 211-250.

[44] Paisley, P. O., \& McMahon, H. G. (2001). School counseling for the twenty-first century: Challenges and opportunities. Professional School Counseling, 5, 106-115.

[45] Pedersen, P.B. (1990). The multicultural perspective as a fourth force in psychology. Journal of Mental Health Counseling, 12, 93_95.

[46] Pedersen, P.B. (1991). Multiculturalism as a generic approach to counseling. Journal of Counseling and Development, 70, 3_14.

[47] Pieterse, A. N., Van Knippenberg, D., \& Van Dierendonck, D. (2013). Cultural diversity and team performance: The role of team member goal orientation. Academy of Management Journal, 56, 782-804. doi: 10.5465/amj.2010.0992

[48] Porter, C. O. L. H. (2005). Goal orientation: Effects on backing up behavior, performance, efficacy, and commitment in teams. Journal of Applied Psychology, 90, 811-818.

[49] Qi, P. (2003). Qingshaonian de wenhua ouxiang gaishi shui [Who should be the teenager's culture

[50] idols?], Journal of Banyuetan, 562(9), 62-63.

[51] Qi Wanxue \& Tang Hanwei. (2004). The social and cultural background of contemporary moral education in China. Journal of Moral Education, Vol.33,No.4.

[52] Rones, M., \& Hoagwood, K. (2000). School-based mental health services: A research review. Clinical, Child and Family Psychology Review, 3, 223-241.
[53] S. Alvin Leung. (2002). Career Counseling in Hong Kong: Meeting the Social Challenges. The Career Development Quarterly. Vol. 50. 237-245.

[54] Seligman, M. E. P. \& Csikszentmihalyi, M. (2000). Positive psychology - an introduction. American Psychologist, 55(1), 5-14.

[55] Seligman, M. E. P., Rashid, T. \& Parks, A. C. (2006). Positive Psychotherapy. American Psychologist, 61, 774-788.

[56] Shek, D.T.L. (1999). The development of counseling in four Asian communities: a critical review of the review papers. Asian Journal of Counseling, 6, 97-114.

[57] Sink, C. A., \& MacDonald, G. (1998). The status of comprehensive guidance and counseling in the United States. Professional School Counseling, 2, 88-94.

[58] Sin, N. L. \& Lyubomirsky, S. (2009). Enhancing well-being and alleviating depressive symptoms with positive psychology interventions: A practice-friendly meta-analysis.Journal of Clinical Psychology: In session, 65(5), 467-487.

[59] Sue A.Stickel \& Julia Yang. (1993). School guidance and counseling in the United States and Taiwan: Parallels and beyond. International Journal for the Advancement of Counseling 16: 229-244.

[60] VandeWalle, D., \& Cummings, L. L. (1997). A test of the influence of goal orientation on the feedback-seeking process. Journal of Applied Psychology, 82, 390-400.

[61] VandeWalle, D. (2001). Goal orientation: Why wanting to look successful doesn't always lead to success. Organizational Dynamics, 30, 162-171.

[62] Van Yperen, N. W., \& Janssen, O. (2002). Fatigued and dissatisfied or fatigued but satisfied? Goal orientations and responses to high job demands.Academy of Management Journal, 45, 1161-1171.

[63] Wang, M., \& Takeuchi, R. (2007). The role of goal orientation during expatriation: A cross-sectional and longitudinal investigation. Journal of Applied Psychology, 92, 1437-1445. doi: 10.1037/00219010.92.5.1437.

[64] Weiyuan Zhang, Xiaolu Hu, \& Mark Pope. (2002). The evolution of career guidance and counseling in the People's Republic of China.The career development quarterly. Vol.50, 226-236.

[65] Wen, M. (2008). The effect of family structure on children's health and well-being: Evidence from the 1999 National Survey of America's Families. Journal of Family Issues, 29, 1492-1519.

[66] Wikipedia. (2014). (concept of role-oriented programming) Available online at: http://en.wikipedia.org/wiki/Role-oriented_programming.

[67] Wong, H. W. (1990). Gongmin he daode jiaoyu [Civic education and moral education] Chun $\mathrm{Yu}$ [Spring Rain], 17.

[68] Zhang, W.W. (2004). Transforming China: Economic reform and its political implications. New York: St. Martin's Press.

[69] Zhang \& Weijun. (1994). American counseling in the mind of a Chinese counselor. Journal of multicultural counseling and development, Vol.22, Issue 2. 